\title{
In Saccharomyces cerevisiae an unbalanced level of tyrosine phosphorylation down-regulates the Ras/PKA pathway
}

\author{
Francesca Magherini $^{\mathrm{a}, 1}$, Stefano Busti ${ }^{\mathrm{b}, 1}$, Tania Gamberi ${ }^{\mathrm{a}}$, Elena Sacco ${ }^{\mathrm{b}}$, \\ Giovanni Raugei ${ }^{\mathrm{a}}$, Gianpaolo Manao ${ }^{\mathrm{a}}$, Giampietro Ramponi ${ }^{\mathrm{a}}$, \\ Alessandra Modesti ${ }^{\mathrm{a}, * *}$, Marco Vanoni ${ }^{\mathrm{b}, *}$ \\ ${ }^{a}$ Dipartimento di Scienze Biochimiche, Università degli Studi di Firenze, Firenze, Italy \\ ${ }^{\mathrm{b}}$ Dipartimento di Biotecnologie e Bioscienze, Università degli Studi di Milano-Bicocca Piazza della Scienza, 2 I-20126 Milano, Italy
}

Received 9 June 2005; received in revised form 1 October 2005; accepted 7 October 2005

\begin{abstract}
The role of tyrosyl phosphorylation/dephosphorylation in the budding yeast Saccharomyces cerevisiae, whose genome does not encode typical tyrosyne kinases, has long remained elusive. Nevertheless, several protein kinases phosphorylating poly(TyrGlu) substrates have been identified. In this work, we use the expression of the low molecular weight tyrosine phosphatase Stp1 from the distantly related yeast Schizosaccharomyces pombe, as a tool to investigate whether an unbalanced level of protein tyrosine phosphorylation affects $S$. cerevisiae growth and metabolism. We correlate the previously reported down-regulation of the phosphotyrosine level brought about by overexpression of Stp1 with a large number of phenotypes indicative of down-regulation of the Ras pathway. These phenotypes include reduction in both glucose- and acidification-induced GTP loading of the Ras 2 protein and cAMP signaling, impaired growth on a non-fermentable carbon source, alteration of cell cycle parameters, delayed recovery from nitrogen starvation, increased heat-shock resistance, attenuated pseudohyphal and invasive growth. Genetic data suggest that Stp1 acts either at, or above, the level of Ras2, possibly on the Ira proteins. Consistently, Stp1 was found to bind to immunoprecipitated Ira2. Since a catalytically inactive mutant form of Stp1 (Stp1 ${ }^{\mathrm{C} 11 \mathrm{~S}}$ ) effectively binds to Ira2 without producing any effect on yeast physiology, we conclude that down-regulation of the Ras pathway by Stp1 requires its phosphatase activity. In conclusion, our data suggest a possible cross-talk between tyrosine phosphorylation and the Ras pathway in yeast.
\end{abstract}

(c) 2005 Elsevier Ltd. All rights reserved.

Keywords: Protein tyrosine phosphatase; Signal transduction; Budding yeast; cAMP; Ras pathway; Gpr1/Gpa2 pathway; Stress resistance

\section{Introduction}

The regulation of cell proliferation and differentiation involves cascades of reversible protein phosphorylation events. The phosphorylation of the amino acid tyrosine

\footnotetext{
* Corresponding author. Tel.: +39026448 3525; fax: +390264483565 .

** Corresponding author.

E-mail address: marco.vanoni@unimib.it (M. Vanoni).

1 They contributed equally to this work.
}

in animal proteins acts as an on-off switch in numerous pathways that regulate growth, cell proliferation, differentiation, development and tumorigenesis (Van der Geer, Hunter, \& Lindberg, 1994). A proper level of tyrosine phosphorylation is obtained through the concerted action of protein kinases and phosphotyrosine protein phosphatases (PTPs, Keyse, 2000).

In the budding yeast Saccharomyces cerevisiae except for two histidine protein kinases, all the protein kinases belong to the Ser/Thr family; "typical members" of the tyrosine kinase family are not encoded in the genome, 
although seven protein kinases that phosphorylate serine/threonine and tyrosine have been reported (Hunter \& Plowman, 1997). Notably, Tyr-phosphorylation has been shown to be essential in controlling the activity of mitogen-activated protein (MAP) kinases. MAP kinase pathways regulate mating, osmosensing, pseudohyphal and invasive growth, spore wall assembly and cell wall biosynthesis (reviewed in Gustin, Albertyn, Alexander, \& Davenport, 1998). Zhu et al. (2000) using a newly developed chip technology identified 27 kinases able to phosphorylate poly(TyrGlu) substrates. Those kinases that use poly(TyrGlu) sequences as a substrate contain near the catalytic region amino acids that are distinct from those that do not. We reported that anti-phosphotyrosine antibodies reveals about 140 spots in a $2 \mathrm{D}$ electrophoresis performed on $S$. cerevisiae cell lysates (Modesti et al., 2001). These two sets of data indicate that tyrosine phosphorylation in budding yeast is a more relevant process than previously suspected. In the $S$. cerevisiae genome, a number of genes encoding putative PTPs have been reported. Six of them encode proteins similar to dual-specificity protein phosphatases (acting on both phospho-Tyr and phospho-Thr (Russell, Moreno, \& Reed, 1989)), and four Tyr-specific phosphatases: Ptp1, Ptp2, Ptp3 and Ltp1, all belong to the non-receptor PTPs sub-family. Ltp1 (Ostanin, Pokalsky, Wang, \& Van Etten, 1995) and Stp1 (Mondesert, Moreno, \& Russel, 1994) are the budding and fission yeast counterparts of the low molecular weight PTP present ubiquitously in mammalian tissues. All these proteins possess the active site motif $(\mathrm{H} / \mathrm{V}) \mathrm{C}(\mathrm{X}) 5 \mathrm{R}(\mathrm{S} / \mathrm{T})$ and share the same catalytic mechanism of classical PTPs (Cirri et al., 1993). The physiological function of the yeast enzymes is unknown but the mammalian low molecular weight PTP shows a broad range of substrates including the PDGF and insulin receptors (Taddei et al., 2000), caveolin (Caselli, Taddei, Manao, Camici, \& Ramponi, 2001) and the p190Rho GAP (Chiarugi et al., 2000). The Ras-PKA pathway plays a crucial role in the control of metabolism, stress resistance and proliferation, in connection with the availability of nutrients. The Ras-GTP/Ras-GDP ratio is controlled by the balance between the activities of guanine nucleotide exchange factors, Cdc25 (Camonis et al., 1986) and Sdc25 (Damak, Boy-Marcotte, Le-Roscouet, Guilbaud, \& Jacquet, 1991), and GTPase Activating Proteins (GAPs) which stimulate Ras-GTPase activity and are encoded by the IRA1,2 genes (Tanaka et al., 1990). In turn, GTP-bound Ras proteins stimulate adenylyl cyclase to yield an increase in intracellular cAMP level that is responsible for the activation of PKA (Toda et al., 1985). Adenylyl cyclase activity in $S$. cerevisiae is controlled by two G-protein systems, the Ras proteins and Gpa2. Glucose has been shown to trigger activation of cAMP synthesis through Gpa2 and its coupled receptor, Gpr1 (Colombo et al., 1998). More recent experiments using a more sensitive assay for Ras2-GTP, showed that glucose addition also triggers a fast increase in the GTP loading of Ras 2 concomitant with the glucose-induced increase in cAMP (Colombo, Ronchetti, Thevelein, Windedckx, \& Martegani, 2004; Rudoni, Colombo, Coccetti, \& Martegani, 2001). Because deletion of GPRI or GPA2 reduces glucose-induced cAMP signaling, the observed enhancement of Ras-GTP loading is not sufficient for full glucose-induced stimulation of cAMP synthesis (Colombo et al., 2004). The cAMP level is also controlled by a low and a high-affinity phosphodiesterase, respectively, encoded by PDE1 and PDE2 (Nikawa, Sass, \& Wigler, 1987; Sass, Field, Nikawa, Toda, \& Wigler, 1986).

Inactivation of Ras causes arrest at the same point in the cell cycle as nutrient depletion, and several phenotypes typically expressed in slow-growing and stationary phase cells are controlled by the Ras-adenylyl cyclase pathway. cAMP-activated PKA phosphorylates a number of proteins involved in metabolism, cell cycle progression, accumulation of glycogen and trehalose and heat-shock resistance. Reduced activity of this pathway leads to growth arrest at the beginning of G1 phase (the same stage at which the cells arrest following nutrient deprivation), causes enhanced levels of glycogen and trehalose and constitutive expression of heat-shock genes (reviewed in Rolland, Winderickx, \& Thevelein, 2002; Thevelein \& deWinde, 1999).

We previously showed that the expression in S. cerevisiae of the low molecular weight PTPase Stp1 from the yeast Schizosaccharomyces pombe affects the pattern of tyrosine phosphorylated proteins (Modesti et al., 2001). In this work, we use the expression of Stp1 as a tool to investigate how an unbalanced level of protein tyrosine phosphorylation affects $S$. cerevisiae growth phenotype and metabolism. We could rule out the hypothesis that the phenotypic effects observed are aspecifically related to overexpression of an heterologous protein, since they were only detected upon expression of functional Stp1, but not of a phosphatase-dead mutant-Stp1 ${ }^{\mathrm{C} 11 \mathrm{~S}}$. In this way, we could correlate down-regulation of tyrosine phosphorylated proteins (Modesti et al., 2001) brought about by overexpression of Stp1 with a large number of phenotypes indicative of down-regulation of the Ras pathway. These phenotypes include reduction in both cAMP signaling and GTP loading of Ras2, impaired growth on non-fermentable carbon source, alteration of cell cycle parameters, delayed recovery from nitrogen 
starvation, increased heat-shock resistance and attenuated presudohyphal/invasive growth. Genetic data suggested that Stp1 acts either at, or above, the level of Ras2, possibly on the Ira proteins. Consistently, Stp1 was found to bind to immunoprecipitated TAP-tagged Ira2. Since the catalitically inactive phosphatase Stp1 ${ }^{\mathrm{C} 11 \mathrm{~S}}$ effectively binds to Ira2 but does not produce any phenotypic effect, we could conclude that down-regulation of the Ras pathway by Stp1 requires its Tyr-phosphatase activity, and that binding of an inactive Stp1 mutant form to Ira2 has no effects on yeast physiology. Thus, our data suggest the existence of a possible cross-talk between tyrosine phosphorylation and the Ras pathway in yeast.

\section{Materials and methods}

\subsection{Strains, growth media and plasmids}

Yeast strains used in this study are listed in Table 1. cDNA fragments corresponding to Stp1, Stp1 ${ }^{\mathrm{C} 11 \mathrm{~S}}$ or Ltp1 were cloned into the pAAH5 plasmid as previously described (Modesti et al., 2001). The mutant Stp1 ${ }^{\text {C11S }}$ contains a single amino acidic substitution in the catalytic site that abolishes the tyrosine phosphatase activity (Modesti et al., 1995). Plasmid pHStp1 (HIS3), pU-Stp1 (URA3) and the corresponding empty vector $(\mathrm{pH}, \mathrm{pU})$ were obtained by swapping the BglII-BglII fragment (containing the LEU2 marker) with a BamHI-BamHI fragment from the appropriate YpD vector (Berben, Dumont, Gilliquet, Bolle, \& Hilger, 1991).

Cells carrying the constitutive $R A S 2^{\text {Val19 }}$ allele were obtained by transformation with the centromeric plasmid YCp50-RAS2 ${ }^{\text {Val19 }}$ (Robinson, Gibbs, Marshall, Sigal, \& Tatchell, 1987) and freshly used after transformation. Plasmid YEplac181-GPA2 $2^{\text {Val132 }}$ or YEplac181-GPA2 ${ }^{\text {Ala273 }}$ (Kraakman et al., 1999) were used to transform W303 cells to obtain strains WGPA2 ${ }^{\mathrm{V} 132}$ and W-GPA2 ${ }^{\mathrm{A} 273}$. Strain W-GUS (W303 background) was obtained by transformation with the integrative plasmid $\mathrm{pKV} 3-\mathrm{d} 2$ containing the HSP12 promoter region fused to the GUS reporter gene (Varela, Praekelt, Meacock, Planta, \& Mager, 1995). Cells were grown at $30^{\circ} \mathrm{C}$ either in YP medium $(1 \%$ yeast extract and $2 \%$ peptone (Biolife) or in synthetic minimal medium (S) containing 0.67\% (w/v) YNB (Difco) and appropriate quantities of the "drop-out" aminoacidnucleotide mixture (Bio101). Carbon sources were either $2 \%(\mathrm{w} / \mathrm{v})$ glucose (D), $2 \%(\mathrm{v} / \mathrm{v})$ ethanol (E), $3 \%$ $(\mathrm{v} / \mathrm{v})$ glycerol $(\mathrm{G})$ or $2 \%(\mathrm{w} / \mathrm{v})$ potassium acetate $(\mathrm{A})$. Solid media contained $2 \%(\mathrm{w} / \mathrm{v})$ agar.

Growth of liquid cultures was monitored as increase in cell number using a Coulter Counter model Z2 (Coulter Electronics, Inc.). The fraction of budded cells was scored by direct microscopic observation on at least 300 cells, fixed in $3.6 \%$ formalin and mildly sonicated. The formula used to calculate $T_{\mathrm{B}}$ (the length of the budded

Table 1

Yeast strains

\begin{tabular}{|c|c|c|}
\hline Strain & Genotype & Source or reference \\
\hline W303-1A & $\begin{array}{l}\text { MATa leu2-3,112 ura3-1 trp1-1 his3-11,15 ade } 2-1 \text { can1-100 } \\
\text { GAL SUC mal }\end{array}$ & Thomas and Rothstein (1989) \\
\hline W303-2d & W303 diploid & Thomas and Rothstein (1989) \\
\hline W303[pAAH5] & W303-1A + pAAH5 & Modesti et al. (2001) \\
\hline W303[pStp1] & W303-1A + pStp1 & Modesti et al. (2001) \\
\hline W303[pStp1 $\left.{ }^{\mathrm{C} 11 \mathrm{~S}}\right]$ & $\mathrm{W} 303-1 \mathrm{~A}+\mathrm{pStp} 1^{\mathrm{C} 11 \mathrm{~S}}$ & Modesti et al. (2001) \\
\hline W303[pLtp1] & W303-1A + pLtp1 & This study \\
\hline PM903 & W303-1A iral::URA3 ira $2:: L E U 2$ & Colombo et al. (1998) \\
\hline PM943 & W303-1A pde1::TRP1 pde $2:: U R A 3$ & Ma, Wera, Van Dijck, and Thevelein (1999) \\
\hline 1407 & W303-1A bcy1::URA3 & Colombo et al. (1998) \\
\hline W-Ras2 $2^{\text {19 }}$ & W303-1A + YCp50-RAS2 $2^{\text {Vall9 }}$ & This study \\
\hline W-GPA2 $2^{\mathrm{V} 132}$ & W303-1A + YEplac181-GPA2 Val132 & This study \\
\hline W-GPA2 $2^{\mathrm{A} 273}$ & W303-1A + YEplac181-GPA2 $2^{\text {Ala273 }}$ & This study \\
\hline W-GUS & W303-1A $H S P 12:: G U S$ & This study \\
\hline YSC1178 & MATa his $3 \Delta 1$ leu $2 \Delta 0$ met $15 \Delta 0$ ura $3 \Delta 0$ HIS3MX6 IRA2-TAP & Ghaemmaghami et al. (2003) \\
\hline HLY 336/8 & MATa/ $\mathbf{\alpha}$ leu2::hisG/LEU2 ura3-52/ura3-52 trp1::hisG/TRP1 & Liu, Styles, and Fink (1993) \\
\hline Neph11 & MAT $\boldsymbol{\alpha}$ leu2::hisG ura3-52 trp1::hisG (HLY 336/8 progenies) & This study \\
\hline Tlys86 & MATa leu2::hisG ura3-52 trp1::hisG (HLY $336 / 8$ progenies) & This study \\
\hline Nephtlys 1186 & $\begin{array}{l}\text { MATa/ } \mathbf{\alpha} \text { leu } 2:: \text { hisG/leu }:: \text { hisG ura3-52/ura3-52 } \\
\text { trp1::hisG/trp1::hisG (Nep11 X Tlys86 cross) }\end{array}$ & This study \\
\hline
\end{tabular}


phase) was

$T_{\mathrm{B}}=\log 2\left(1+F_{\mathrm{B}}\right) T$

where $F_{\mathrm{B}}$ is the percentage of the budded cells and $T$ is the population doubling time $(T=\ln 2 / \alpha$, where $\alpha$ is the experimentally determined growth rate).

For nitrogen starvation (Vanoni \& Johnson, 1991), exponentially growing cells were harvested by filtration, washed and resuspended in starvation-medium $(2 \%$ glucose, $0.17 \%$ YNB w/o ammonium sulphate (Difco), supplemented with the nutritional requirements at $10 \%$ of the level normally required). Cells were incubated at $30{ }^{\circ} \mathrm{C}$ for increasingly periods of time. Upon nitrogen source re-addiction, growth recovery was monitored as bud emergence and increase in cell number.

\subsection{Flow cytometric analysis}

Samples of growing cultures were collected (about $2 \times 10^{7}$ cells) and fixed in $70 \%$ ethanol before analysis. To obtain protein distribution, cells were stained with fluorescein isothyocyanate solution. The intensity of green fluorescence $(>520 \mathrm{~nm})$ was measured on at least $10^{5}$ cells with a FACS IV fluorescence-activated cell sorter (Becton \& Dickinson), equipped with an argon ion laser, essentially as described in Vanoni, Vai, Popolo, and Alberghina (1983).

\section{3. $c A M P$ determination}

For determination of cAMP intracellular level, $100 \mathrm{mM}$ glucose or $2 \mathrm{mM}$ 2,4-dinitrophenol were added to cells grown in SD medium containing 3\% glycerol and $0.01 \%$ glucose. For the induction with 2-4-dinitrophenol cells were incubated in $25 \mathrm{mM}$ MES buffer ( $\mathrm{pH}$ 6) for $10 \mathrm{~min}$ before addition of $2 \mathrm{mM}$ 2,4-dinitrophenol. Cells were taken by filtration at the time intervals indicated, immediately quenched in $n$-butanol-saturated $1 \mathrm{M}$ formic acid and frozen in liquid nitrogen (Jiang, Davis, \& Broach, 1998). Cell debris was removed by centrifugation and the clear supernatants were freeze dried in a Speed Vac. The cAMP level in the lysates was determined by a cAMP enzyme immunoassay (EIA) system (Amersham Pharmacia).

\subsection{Determination of RAS2-GTP level}

Ras2-GTP was detected using a pull-down assay essentially as described by Rudoni et al. (2001). Briefly, cells were grown and collected as described above for cAMP determination. Cells were suspended in ice-cold lysis buffer (25 mM HEPES, pH 7.5, $150 \mathrm{mM} \mathrm{NaCl}$,
$1 \% \mathrm{NP}-40,0.25 \% \mathrm{Na}$ deoxycholate, $10 \%$ glycerol, $25 \mathrm{mM} \mathrm{NaF}, 10 \mathrm{mM} \mathrm{MgCl} 2,1 \mathrm{mM} \mathrm{Na} \mathrm{VO}_{4}, 10 \mu \mathrm{g} / \mathrm{ml}$ leupeptin and $10 \mu \mathrm{g} / \mathrm{ml}$ aprotinin) and disrupted with glass beads in a Fastprep instrument (Savant). Cleared supernatants (200-400 $\mu \mathrm{g}$ protein) were incubated with a glutathione- $S$-transferase-Raf1 Ras binding domain (GST-RBD) fusion protein pre-bound to glutathionesepharose for $1 \mathrm{~h}$ at $40^{\circ} \mathrm{C}$. The beads were washed with PBS containing $1 \mathrm{mM}$ EDTA and subsequently with PBS buffer containing 1\% Triton X-100, 10\% glycerol, $1 \mathrm{mM}$ EDTA, $0.5 \mathrm{mM}$ DTT, $1 \mu \mathrm{g} / \mathrm{ml}$ aprotinin, $1 \mu \mathrm{g} / \mathrm{ml}$ leupeptin, $1 \mathrm{mM}$ PMSF, $0.1 \mathrm{mM} \mathrm{Na} \mathrm{VO}_{4}$. Bound proteins were eluted with $2 \times$ SDS-sample buffer $(100 \mathrm{mM}$ Tris-HCl pH 6.8, 2\% $\beta$-mercaptoethanol, 4\% SDS, $0.2 \%$ bromophenol blue, $20 \%$ glycerol), separated by SDSPAGE, blotted to nitrocellulose, immunodecorated with anti-Ras 2 polyclonal antibodies (Santa Cruz Biotechnology) and revealed with ECL Western blotting analysis system (Amersham Pharmacia Biotech). Total Ras 2 protein was detected on cleared lysate (3-5 $\mu \mathrm{g}$ of total protein) by Western blotting using the same anti-Ras2 antibodies. The total protein concentration was estimated by DC protein assay (Bio-Rad) following the manufacturer's instructions. The bands were quantitated by densitometric analysis (NIH-Image software) and the fraction of Ras2.GTP was calculated taking into account the amount of protein loaded.

\subsection{Ethanol and glycogen determination}

For glycogen and ethanol determination, cells were grown in SD medium containing 3\% glycerol and $0.01 \%$ glucose in exponential phase $\left(3 \times 10^{7}\right.$ cells $\left./ \mathrm{ml}\right)$. After addition of glucose at a final concentration of $100 \mathrm{mM}$, the incubation was performed for $120 \mathrm{~min}$. During the incubation time $1 \mathrm{ml}$ of cleared supernatant was collected to estimate the ethanol production. Ethanol was determined using the alcohol dehydrogenase kit (TC Roche Diagnostics).

For glycogen determination, the cells were collected at the time intervals indicated, washed once with cold water, weighed (at about $50 \mathrm{mg}$ wet mass) and resuspended in $0.5 \mathrm{ml}$ of $10 \%$ perchloric acid and the same volume of glass beads. The mixture was immediately frozen in liquid nitrogen. Samples were thawed on ice, vortexed by five pulses for 1 min and centrifuged at low speed. Glycogen was determined enzimatically by incubation of $100 \mu \mathrm{l}$ of the acid extract, neutralised with $5 \mathrm{M} \mathrm{K}_{2} \mathrm{CO}_{3}$, with $100 \mu \mathrm{l}$ of 73 units/ml amyloglucosidase from Aspergillus niger in $0.4 \mathrm{M}$ sodium acetate $\mathrm{pH}$ 4.8 (TC Roche) at $50{ }^{\circ} \mathrm{C}$ for $3 \mathrm{~h}$. After addition of $150 \mu \mathrm{l}$ of $10 \%$ perchloric acid and centrifugation at top speed, 
glucose was measured in $100 \mu \mathrm{l}$ of cleared supernatant using the glucose-dehydrogenase method (TC Roche) (Müller, Rouveyre, Crecelius, \& Bandlow, 1998).

\subsection{Heat-shock resistance}

For determination of heat-shock resistance, samples were taken from exponentially growing or from stationary phase cultures. Cells were collected by centrifugation, resuspended in water and heated at $51^{\circ} \mathrm{C}\left(\right.$ or $\left.47^{\circ} \mathrm{C}\right)$ for the time periods indicated. After cooling, cells were serially diluted and spreaded on nutrient plates (about 1000 cells). Resulting colonies were counted after 3 days of growth at $30^{\circ} \mathrm{C}$.

\section{7. $\beta$-Glucoronidase assay}

To determine $\beta$-glucoronidase specific activity, WGUS cells were grown at $30^{\circ} \mathrm{C}$ in minimal medium containing ethanol as sole carbon source. At time point zero, glucose was added to a final amount of $2 \%(\mathrm{w} / \mathrm{v})$ and samples of cultures were taken at the indicated periods. Alternatively, cultures growing at $24^{\circ} \mathrm{C}$ in glucose minimal medium were shifted to $37^{\circ} \mathrm{C}$ to induce the expression of the reporter gene. Cells were rapidly harvested by filtration, washed with ice-cold water and resuspended in GUS-extraction buffer $\left(50 \mathrm{mM} \mathrm{NaPO}_{4}, \mathrm{pH} 7.0 ; 10 \mathrm{mM}\right.$ $\beta$-mercaptoethanol; $10 \mathrm{mM} \mathrm{Na} 2$ EDTA; $0.1 \%$ sodium lauryl sarcosine; $0.1 \%$ Triton X-100; $1 \mathrm{mM} \mathrm{PMSF).}$ Cells were disrupted with glass beads in a Fastprep instrument (Savant) and protein extracts were clarified by centrifugation at $13,000 \mathrm{rpm}$ for $2 \mathrm{~min}$. $\beta$-Glucoronidase activity was measured by a spectrophotometric assay using $p$-nitrophenyl $\beta$-D-glucuronide (PNPG) as substrate, essentially as previously described (Wanke et al., 1999): the assay was performed at room temperature and the reaction was stopped by the addiction of one volume of $\mathrm{K}_{2} \mathrm{CO}_{3}$. Absorbance was measured at $415 \mathrm{~nm}$ against a stopped, blank reaction to which identical amounts of extracts and substrate had been added. Protein content was measured using the Bio-Rad protein assay reagent (Bio-Rad).

\subsection{Pull-down assay with Ira2-TAP-taggedprotein}

Strain YSC1178 (S288C background), expressing a TAP-tagged version of Ira2, was purchased from Open Biosystems. Tandem affinity purification was performed according to Rigaut et al. (1999) with minus modification. Twenty millilitres of exponentially growing W303-1A or YSC1178 strain transformed with either the pAAH5-Stp1, the pAAH5-Stp1 ${ }^{\text {C11S }}$ or the pAAH5 con- trol plasmid were harvested and lysated with a Fast Prep instrument (Bio101) in NP40 buffer $\left(6 \mathrm{mM} \mathrm{Na}_{2} \mathrm{HPO}_{4}\right.$, $4 \mathrm{mM} \mathrm{NaH}_{2} \mathrm{PO}_{4} \cdot \mathrm{H}_{2} \mathrm{O}, 1 \%$ Nonidet P- $40,150 \mathrm{mM} \mathrm{NaCl}$, $2 \mathrm{mM}$ EDTA, $50 \mathrm{mM} \mathrm{NaF}, 0,1 \mathrm{mM} \mathrm{Na} \mathrm{VO}_{4}$ ) plus proteases inhibitors cocktail (Sigma). One milligram of total proteins were incubated with $30 \mu$ l of IgG Sepharose 6 Fast Flow (Pharmacia Biotech) prepared as a 1:1 slurry with NP40 buffer at $4{ }^{\circ} \mathrm{C}$ overnight.

The beads were washed four times with NP40 and once in Tris- $\mathrm{HCl} 50 \mathrm{mM}$ pH 7.5 and directly resuspended in Laemmli buffer. Western-blot analysis was performed using anti-Stp1 polyclonal antibodies.

\subsection{Pseudohyphal and invasive growth assays}

Strain HLY336/8 and its progeny (Neph11, Tlys86 and Nephtlys1186) used in this set of experiments are congenic to the $\Sigma 1278$ benetic background. Low ammonium medium (SLAD: $2 \%$ glucose, $0.17 \%$ YNB w/o ammonium sulphate (Difco), $50 \mu \mathrm{M}$ ammonium sulphate, $2 \%$ agar) for induction of pseudohyphal growth has been described (Gimeno, Ljungdahl, Styles, \& Fink, 1992). Cells were grown over-night on selective SD medium, streaked on SLAD plates and incubated at $30{ }^{\circ} \mathrm{C}$ for 3-7 days. Representative microcolonies were photographed directly on agar plates with a Cool snap camera (RS photometries) mounted on a Nikon microscope at $25 \times$ magnification.

The invasive growth assay was performed as previously described (Roberts \& Fink, 1994). Briefly, cells were spotted on YPD plates, incubated at $30^{\circ} \mathrm{C}$ for 3 days and for an additional 2 days at $24^{\circ} \mathrm{C}$. Plates were then photographed, washed with a gentle stream of deionized water and photographed again.

\section{Results}

\subsection{Stp1 expression affects cell growth and cell cycle parameters more severely on cells growing on non-fermentable carbon sources}

Many putative Stp1 substrates in budding yeast have been identified as enzymes involved in carbohydrate metabolism (Modesti et al., 2001). Preliminary experiments indicated that on plates supplemented with nonfermentable carbon sources, colonies of several yeast strains (including W303, SP1 and S288C) expressing Stp1 appeared a little later and were of smaller size. W303 was thus chosen as a reference strain, and used in later experiments unless indicated otherwise. In a first set of experiments, we examined kinetic growth parameters of W303[pStp1] cells in liquid media supplemented 
with different carbon sources. These analyses indicate that Stp1 expression affects growth and cell cycle kinetics and that this effect is more pronounced on poorer carbon sources (Table 2). Namely, in W303[pStp1] cells growing on SCD no significative difference in duplication times $(T)$ or in the relative length of the budded phase (TB/T) were observed. A minor, but consistent reduction $(\sim 10 \%)$ in the average protein content was measured by FACS analysis (data not shown). When the W303[pStp1] strain was grown at slower growth rates, i.e. by supplementing media with the non-fermentable carbon sources ethanol, glycerol and acetate, more striking differences were observed with the isogenic control. The duplication time dramatically increased and the elongation of the cell cycle length was completely restricted to the unbudded, G1 phase indicating that the G1/S transition is exquisitely sensitive to unbalanced tyrosine phosphorylation. We also consistently observed that stationary phase W303[pStp1] cells stop growth at a lower cell density and take longer to re-enter balanced exponential growth when compared to the isogenic control (data not shown).

Overexpression of a catalitically inactive mutant form of Stp1 (Stp1 $\left.{ }^{\mathrm{C} 11 \mathrm{~S}}\right)$ had no effect on growth and cell cycle progression (Table 2), indicating that the observed effects are specially related to Stp1 catalytic activity. Moreover, in keeping with previous reports (Ostanin et al., 1995), no effect was detected upon overexpression of Ltp1, the S. cerevisiae homologous of Stp1 (see Section 4).

\subsection{Stp1 expression delays the G0/1 to $S$ transition in cells recovering from nitrogen starvation}

Yeast cells deprived of essential nutrients have been shown to enter progressively deeper starvation states requiring a longer lag phase to re-enter the cell cycle (Iida \& Yahara, 1984; Vanoni \& Johnson, 1991), similarly to what has been reported for mammalian cells at different times after confluence (Augenlicht \& Baserga, 1974). To better characterize the role played by Stp1 overexpression in the G0/1 to $S$ transition, cells were synchronized at START B by nitrogen starvation of increasing length (16 and $170 \mathrm{~h}$ ). Recovery from the block was followed by scoring the time-course of budding index and cell concentration. In wild-type W303 nitrogen-starved for $16 \mathrm{~h}$, bud emergence can be observed as early as 90 min after nitrogen re-feeding (Fig. 1A, open circles), whereas a ca. 20 min delay (reproducibly detected in five independent experiments) can be observed in the Stp1overexpressing strain (Fig. 1A, open squares). After the longer starvation time, the wild-type strain takes as long

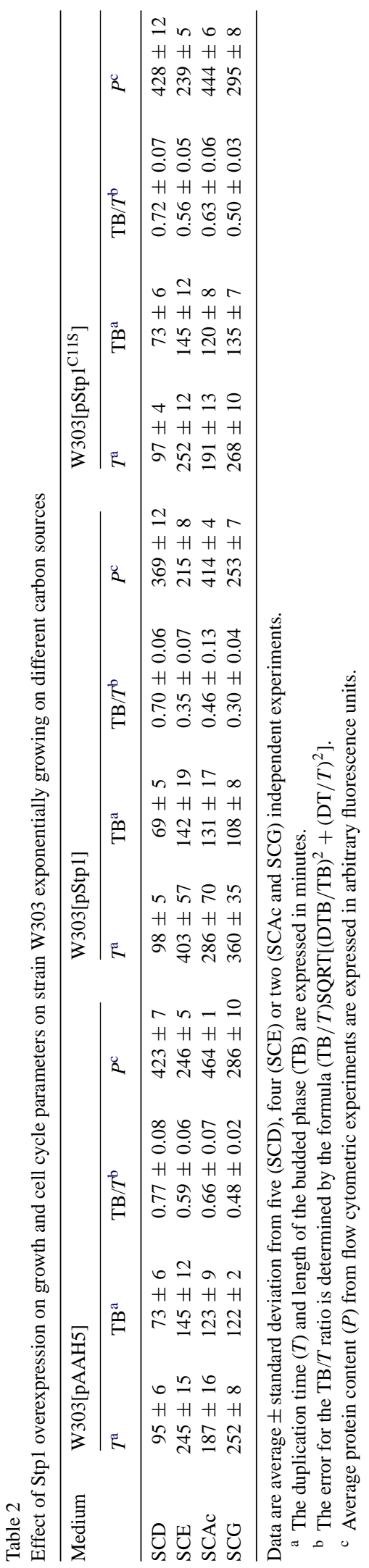




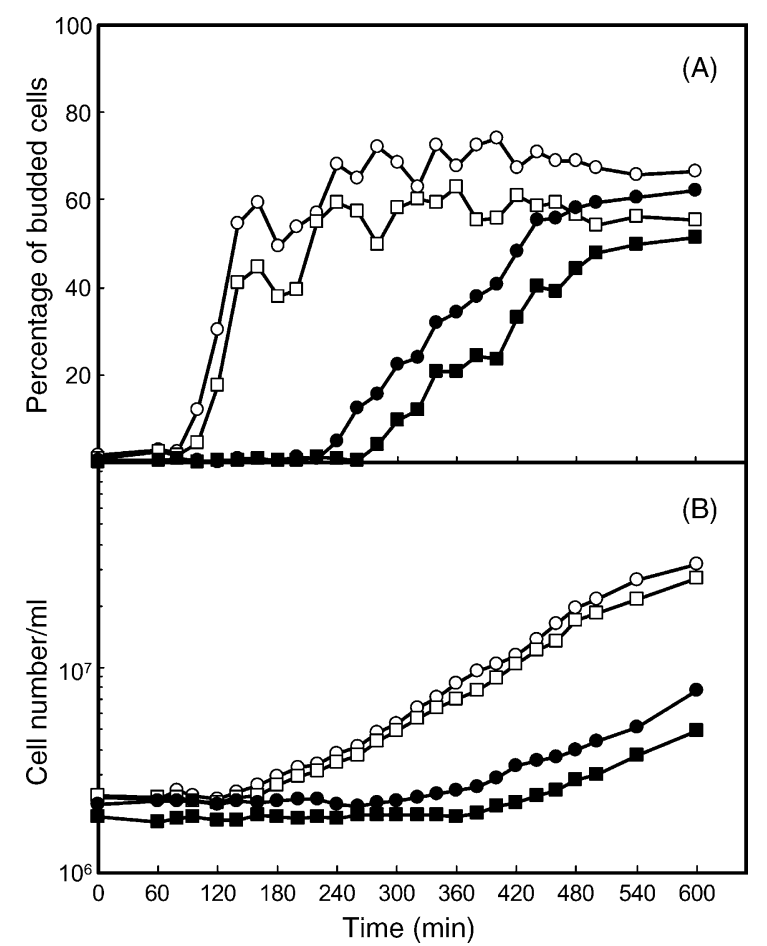

Fig. 1. Stp1 expression delays recovery from nitrogen starvations of increasing duration. Cells of strain W303[pStp1] (squares) and W303[pAAH5] (circles) were starved for 16 (open symbols) or $168 \mathrm{~h}$ (close symbols). Cells were resuspended in nitrogen-containing medium at $t=0$. The fraction of budded cells (A) and the cells density (B) are shown

as 240 min before cells start to bud (Fig. 1A, close circles) while the Stp1 expressing strain shows a reproducible 40 min delay to execute START (Fig. 1A, close squares). W303[pStp1] cells present similar delays in cell division as monitored by the increase in cell number (Fig. 1B). The delay in recovery specifically requires the catalytic activity of Stp1, since such a delay is not observed in W303[pStp1 ${ }^{\mathrm{C} 11 \mathrm{~S}}$ ] strain (data not shown). Taken together with data presented in the previous paragraph, these results indicate that the decreased phosphotyrosine level brought about by Stp1 expression (Modesti et al., 2001) negatively modulate execution of START B.

\subsection{The phenotype of cells expressing Stp1 is consistent with a down-regulation of the cAMP pathway}

The delayed execution of START B suggests that Stp1-overexpressing strains may present defects in the Ras/PKA pathway. To further examine this point, several Ras/PKA-related phenotypes were scored. The expression of Stp1 increases heat-shock resistance in stationary phase, an effect that becomes more evident at longer shock times (Fig. 2B). The increased heat-shock resistance is even more dramatic during exponential growth (Fig. 2A). Consistently with up-regulation of heat-shock resistance, a stress-inducible reporter gene (HSP12-GUS) was induced faster and to a higher extent in Stp1-overexpressing strain upon shift from 24 to $37^{\circ} \mathrm{C}$ (Fig. 2C). Conversely, W303[pStp $1^{\mathrm{C} 11 \mathrm{~S}}$ ] cells do not display any appreciable change in thermo tolerance (Fig. 2A) and in expression of the stress-inducible reporter gene (Fig. 2C).

In a second set of experiments, glycogen content, heat-shock resistance, ethanol production and expression of a STRE-controlled reporter gene were scored in the W303[pStp1] strain and compared to the isogenic control during the transition from respiratory to fermentative growth. The fast activation of the Ras-cAMP pathway triggered by glucose addition results in mobilization of storage carbohydrates (Francois, Villanueva, \& Hers, 1998; Kraakman et al., 1999; Smith, Ward, \& Garrett, 1998; Van der Plaat, 1974), such as glycogen, and increased heat-shock sensitivity, partly mediated by the rapid shutdown of genes containing STRE elements in their promoters (Moskivna, Schuller, Mauer, Mager, \& Ruis, 1998; Ruis \& Schuller, 1995). Stp1 expressing cells growing on synthetic media supplemented with a non-fermentable carbon source, accumulate higher levels of intracellular glycogen than their wild-type counterparts. Both the W303[pStp1] and W303[pAAH5] strains showed however a very similar mobilization rate (Fig. 3A, squares and circles, respectively). Essentially similar results were obtained when heat-shock sensitivity and the activity of the STRE-reporter gene were scored. In fact both the activity of the STREreporter gene (Fig. 3C) and, most notably, heat-shock resistance (Fig. 3B) were significantly higher in Stp1overexpressing cells during respiratory growth (Fig. 3C, zero time point) than in the W303[pAAH5]. These results thus indicate that the typical fluctuations observed in the scored parameters upon glucose addition to respiring cells are observed also in Stp1-expressing cells, though the increase of glycogen level and heat-shock resistance are consistent with an attenuation of the Ras/PKA pathway.

We showed that the extent of tyrosine phosphorylation of the glycolytic enzyme Adh1 is affected by Stp1 expression (Modesti et al., 2001). This constitutive enzyme catalyses the final step in fermentation leading to a reduction of acetaldehyde to ethanol. We determined the level of ethanol production of the recombinant strains in comparison to the control strain. As shown in Fig. 3D, W303[pStp1] cells growing in derepressing medium and challenged with $100 \mathrm{mM}$ glucose accumulated ethanol in 

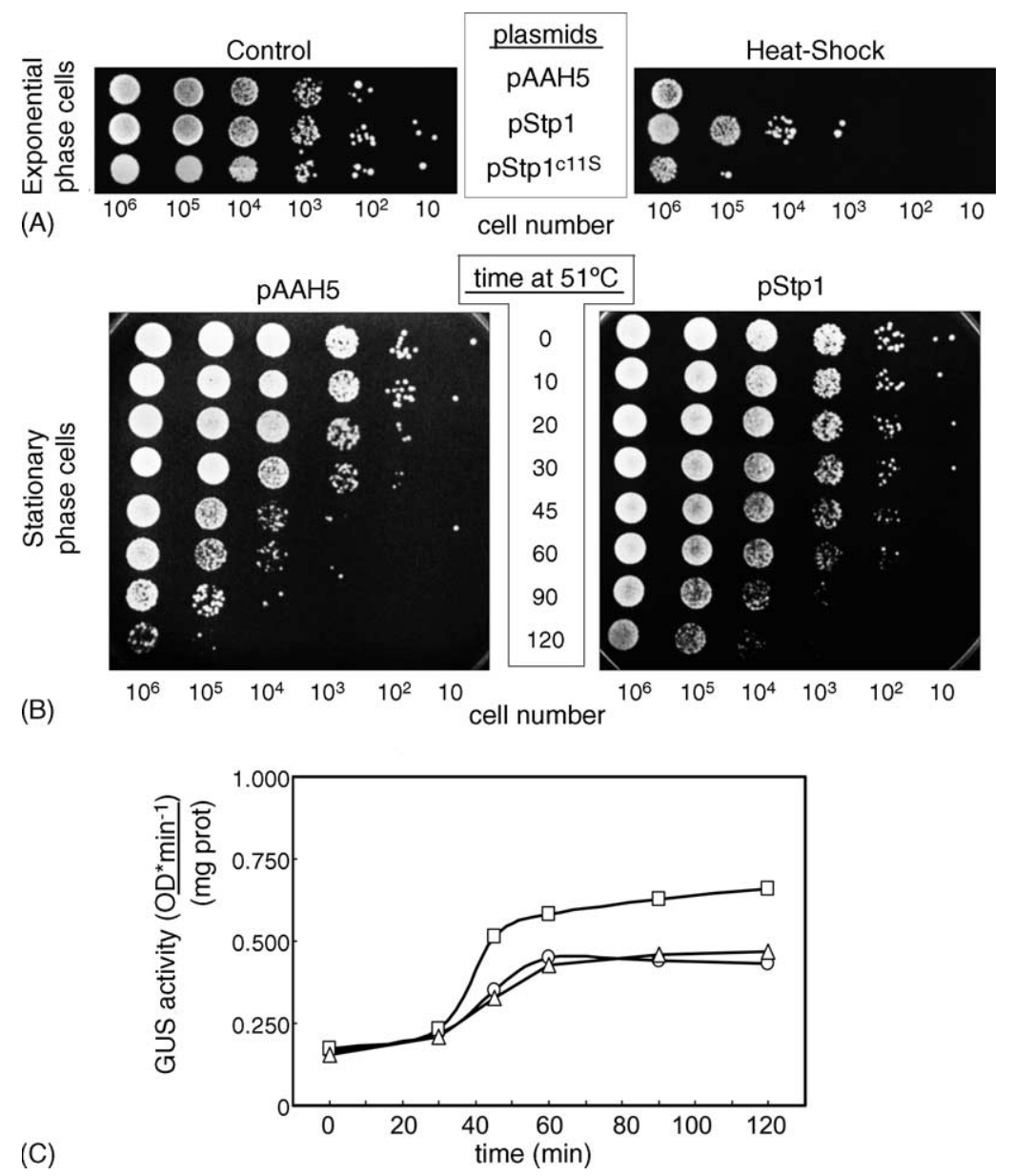

Fig. 2. Stp1 overexpression increases heat-shock resistance and expression of a STRE-driven reporter gene. Control (W303[pAAH5]), Stp1 (W303[pStp1]) and Stp1 ${ }^{\mathrm{C} 11 \mathrm{~S}}$ (W303[pStp1 ${ }^{\mathrm{C} 11 \mathrm{~S}}$ ]) expressing cells were grown in SD-glucose medium to mid-logarithmic phase $\left(5 \times 10^{6}\right.$ cells/ml, upper panels) or to saturation (middle panels). Aliquots of cultures were heated at $51{ }^{\circ} \mathrm{C}$ for 20 min (upper panels) or for the indicated time periods (bottom panels). After cooling on ice, treated and untreated cells were serially diluted, spotted on plates $\left(10^{6}-10^{1}\right.$ cells in a $5 \mathrm{ml}$ volume $)$ and scored after incubation at $30^{\circ} \mathrm{C}$ for $48 \mathrm{~h}$. In the lower panel, dosage of the $\beta$-glucoronidase activity upon thermal stress. W-GUS[pAAH5] (circles), W-GUS[pStp1] (squares) or W-GUS[pStp1 ${ }^{\mathrm{C} 11 \mathrm{~S}}$ ] (triangles) were grown at $24^{\circ} \mathrm{C}$ and shifted to $37^{\circ} \mathrm{C}$ to induce the expression of the GUS-reporter gene.

the medium at a slower rate than the control strain, so that 120 min after glucose addition, the ethanol level in the W303[pStp1] strain was less than $30 \%$ that of the isogenic control, despite the fact that the response of both strains to glucose challenge was very similar in terms of cell cycle re-entry as judged by increase in cell number (Fig. 3C and insert).

\subsection{Stpl attenuates cAMP signaling}

Since most of the previously examined phenotypes can be related to an attenuation of cAMP level, we investigated cAMP signaling after addition of glucose or after induction of intracellular acidification. In fact, the addition of glucose to yeast cells grown on a non- fermentable carbon source triggers a rapid rise in the intracellular cAMP level and intracellular acidification (addition of 2,4-dinitrophenol, DNP, at pH 6.0) is known to trigger a more lasting and higher cAMP signal. The amplitude of this cAMP response is largely reduced in the W303[pStp1] strain, compared to the isogenic W303[pAAH5] strain, both after induction with glucose and after induction with DNP (Fig. 4A and B).

Cyclic AMP signaling was accompanied by an increase in the intracellular level of Ras-GTP. This increase is more evident when the cAMP peak is induced by acid treatment (Colombo et al., 1998), but it has nevertheless been reported also following glucose stimulation (Colombo et al., 2004; Rudoni et al., 2001). A pulldown assay that makes use of the Ras binding domain of 


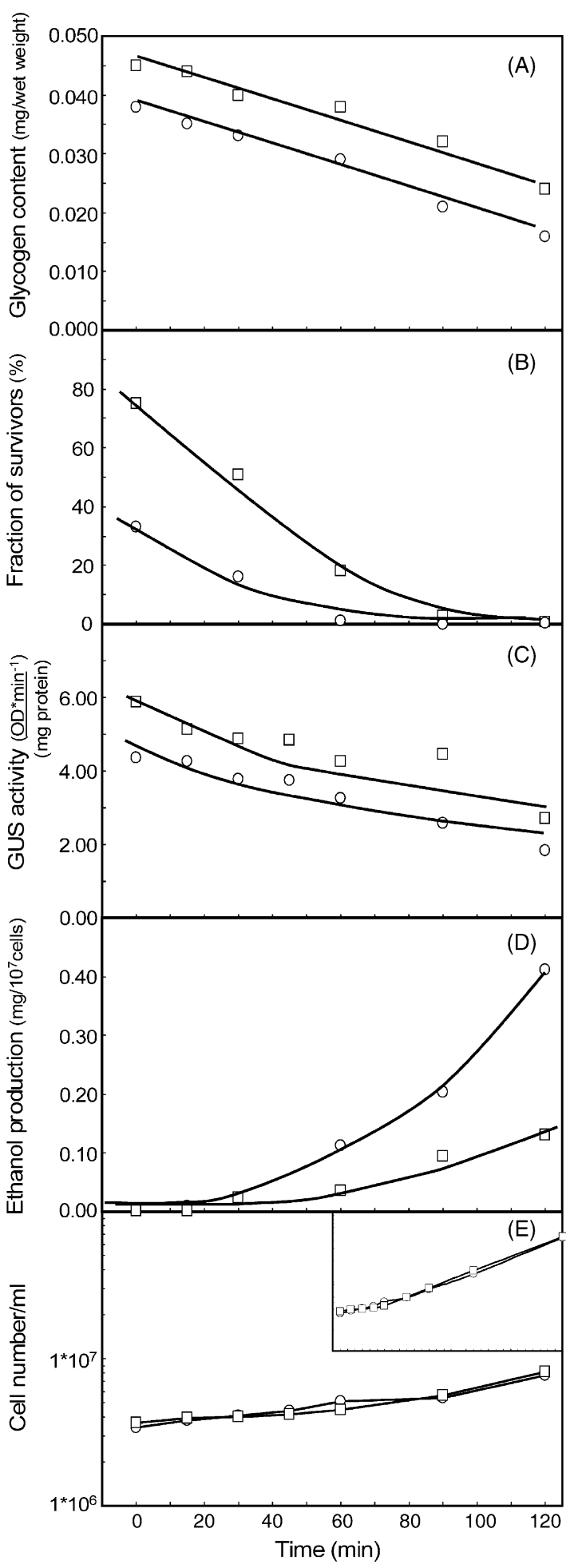

Raf1 was thus used to measure the intracellular RasGTP levels following stimulation of cAMP signaling by glucose and intracellular acidification. At time $=0$ of the experiment about $0.5-1 \%$ of total Ras was in the GTP-bound form in both strains, a value in close agreement with previous measurements using the same method (Rudoni et al., 2001). Results, reported in Fig. 4C and $\mathrm{D}$, respectively, indicate that reduction in Ras-GTP signaling closely parallels that observed with cAMP.

\subsection{Mapping the major Stp1 site of action in vegetatively growing cells}

In yeast, both Ras2 and Gpa2 proteins mediate glucose-induced cAMP signaling. The effect of Stp1 overexpression in strains harboring mutations in genes involved in cAMP signaling was tested by assaying heatshock resistance. Although the effect is slightly smaller than in wild-type cells (Fig. 5A), Stp1 overexpression increases heat-shock resistance also in strains expressing Gpa $2^{\text {Val132 }}$ (B) - an activated GTP-bound mutant (Lorenz \& Heitman, 1997) - or Gpa2 $2^{\text {Ala273 }}$ (C), that shows a strong reduction of GTPase activity (Xue, Batlle, \& Hirsch, 1998). On the contrary, deletion of the IRA1,2 genes or mutational activation of the RAS2 gene (Fig. 5D and E) made these strains completely insensitive to the action of Stp1. These results suggest that the major target(s) of Stp1 activity are in the Ras2 branch of the cAMP pathway. The effect of Stp1 overexpression was also abolished in cells harboring activating mutations in genes encoding proteins acting downstream of Ras, such as the pde $1 \Delta p d e 2 \Delta$ and bcyl $\Delta$ strains (Fig. 5F and G).

\subsection{Stpl binds to Ira2 in vivo}

Experiments reported in the above paragraph suggest that Stp1 modulates the cAMP pathway either at, or above, the level of Ras2, possibly by acting on the Ira proteins. If this is the case and if the interaction between the two proteins is strong enough, then the Stp1 phosphatase could be found associated to the Ira proteins in vivo. Pull-down experiments were conducted on a strain carrying a TAP-tagged Ira2 protein. Prelim-

Fig. 3. Effect of overexpression of the Stp1 phosphatase on glucoseinduced glycogen mobilization (A), loss of heat resistance (B), reduction in the expression of a STRE-driven reporter gene (C) ethanol accumulation (D) and cell growth (E). Strains are W303[pStp1] (squares) and W303[pAAH5] (circles). Glucose is added at time 0 to cells pregrown in media supplemented with a non-fermentable carbon source. Data in the insert of (E) refers to a larger time window (0-300 min) that allows to follow the glucose-induced upregulation of cell growth and division. 

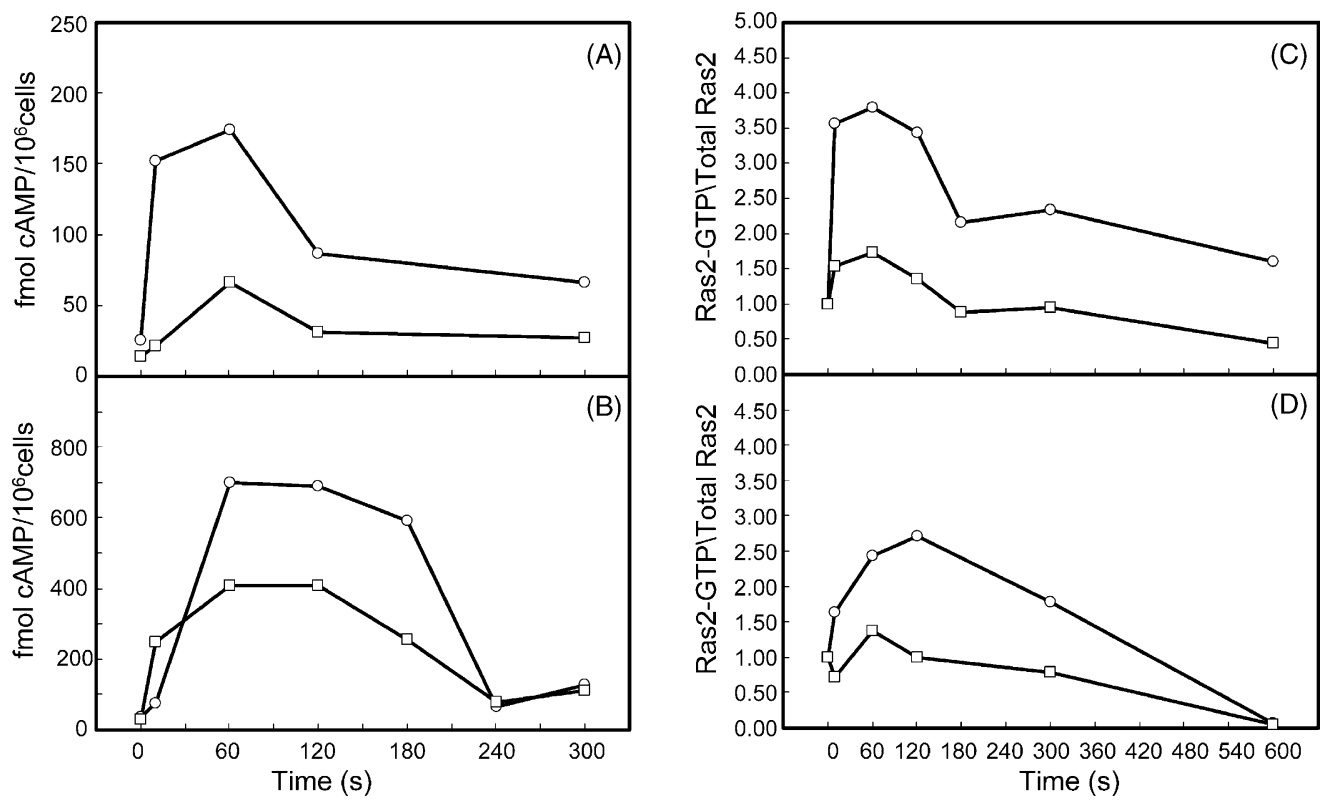

Fig. 4. Stp1 overexpression attenuates cAMP signaling and Ras activation. Strains are W303[pStp1] (squares) and W303[pAAH5] (circles). (A and B) Time course of intracellular cAMP accumulation induced by $100 \mathrm{mM}$ glucose (A) and $2 \mathrm{mM} \mathrm{2,4} \mathrm{dinitrophenol} \mathrm{(B)} \mathrm{added} \mathrm{at} \mathrm{time} 0$. (C and D) Quantitative analysis of Ras2-GTP levels after addition of $100 \mathrm{mM}$ glucose to glucose-starved cells (C) or $2 \mathrm{mM} 2,4$ dinitrophenol (D). Ras2 proteins were separated by SDS-PAGE and detected by immunoblotting with anti Ras2 polyclonal antibodies. The ratio of Ras2.GTP/total Ras2 was determined by densitometric analysis. Data are plotted as the relative increase over time, the value at time 0 being taken as 1 .

inary experiments confirmed that the TAP-tagged strain responded to Stp1 overexpression as our reference strain, W303 (data not shown). The tagged Ira2 protein was recovered from total cell extract by affinity selection on the IgG beads. After extensive washing, the beads and the complex associated were directly analysed by SDS-PAGE and western blot. The association of Stp1 to Ira2 was proved using anti-Stp1 antibodies (Fig. 6, lane 8). In order to formally prove that binding of Stp1 to Ira2 takes place also in the absence of Stp1 catalytic activity, the same experiment was repeated with a strain expressing Stp1 ${ }^{\mathrm{C} 11 \mathrm{~S}}$. As shown in Fig. 6, lane 9, we could successfully purify also the mutant $\operatorname{Stp} 1^{\mathrm{C} 11 \mathrm{~S}}$ phosphatase. Thus, Stp1 binding to Ira2 takes place also in the absence of physiological effects. This rules out that Stp1-mediated effects derive by titration or steric hinderance or masking of specific interactions. Conversely, no Stp1 band was detected after performing the purification procedure in control strains (W303[pStp1], $\left.\mathrm{W} 303\left[\mathrm{pStp} 1^{\mathrm{C} 11 \mathrm{~S}}\right]\right)$ expressing a non-tagged version of Ira2 (Fig. 6, lanes 7 and 8). The tagged Ira2 was not detectable by purified rabbit IgG (data not shown). This is hardly surprising, since their exceedingly low abundance makes Ira proteins hardly detectable, if at all, by this technique (Gavin et al., 2002; Ghaemmaghami et al., 2003).

\subsection{Stpl overexpression attenuates pseudohyphal/invasive growth}

In S. cerevisiae the Ras/PKA pathway is known to be involved in the major differentiation pathways, namely pseudohyphae formation and invasive growth. Different environmental stimuli induce dimorphic switch in haploids (invasive growth) and diploids (pseudohyphal growth) cells. The triggering signal appears to be glucose starvation in haploids (Cullen \& Sprague, 2000; Roberts \& Fink, 1994) and nitrogen starvation in diploids (Gimeno et al., 1992). In both cases, a major alteration in cell morphology is observed so that cells become elongated and do not separate after cytokinesis, generating cell chains that invade the growth substrate. The complex underlying molecular mechanisms are shared in both cell types and involve the Ras/PKA pathway (reviewed in Palecek, Parikh, \& Kron, 2002).

The diploid strain Nephtlys1186 (background $\Sigma 1278$ b, i.e. the standard strain used in pseudohyphae experiments) harboring either the Stp1-overexpressing plasmid or the empty control plasmid was assayed for pseudohyphal growth on SLAD plates. After 5 days of incubation, microcolonies were scored as negative (-), positive (+) or strongly positive (++) for pseudohyphal growth (see Fig. 7A). The diploid Nephtlys1186[pStp1] 

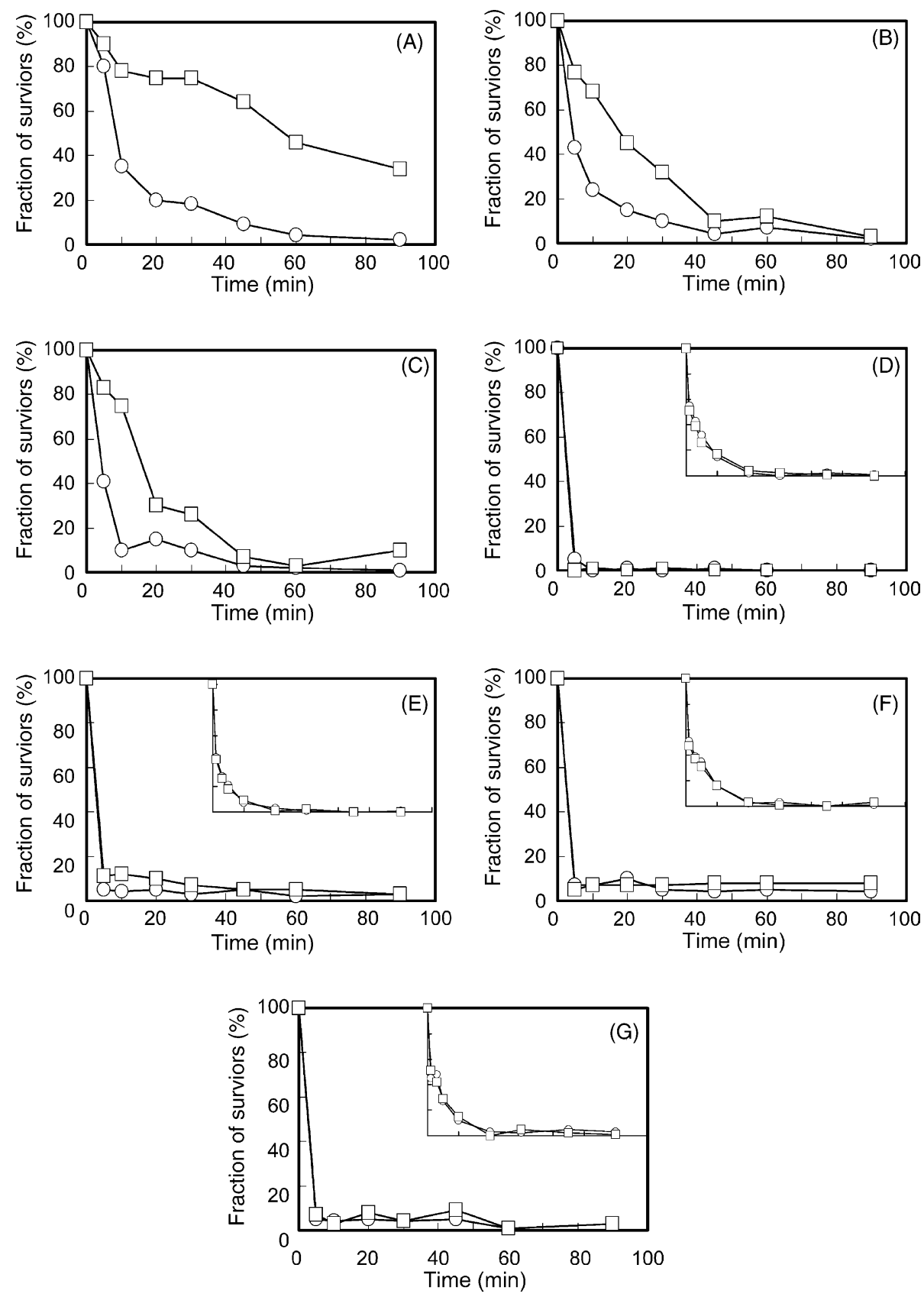

Fig. 5. Mutations in the Ras2 - but not the Gpr1/Gpa2 - branch of the cAMP signaling pathway abrogate the effect of Stp1 overexpression. Strains W303-1A (A), GPA2 ${ }^{\text {Val132 }}$ (B), GPA2 $2^{\operatorname{Ala} 273}$ (C), ira1 $\Delta$ ira2 $\Delta$ (D), RAS2 Val19 (E), pde1pde $2 \Delta$ (F) and bcy1 $\Delta(\mathrm{G})$ transformed with Stp1(squares) or control (circle). Heat-shock resistance was determined by incubation at $51^{\circ} \mathrm{C}$ for the indicated time period. Data in the inserts of (B) and (C) refer to cells whose heat-hock resistance was determined by incubation at $47^{\circ} \mathrm{C}$ for the indicated time period (scale of axes is the same as in all panels).

strain exhibited a strongly attenuated pseudohyphae growth, nearly $60 \%$ of the micro-colonies being scored as negative (Fig. 7B). Moreover, Stp1 expression was also effective in inhibiting pseudohyphae formation in strains expressing either Gpa $2^{\text {Val132 }}$ or Ras $2^{\text {Val19 }}$, which are known to enhance filamentous growth.
The effect of Stp1 overexpression on invasive growth was tested by an agar invasion assay. Consistent with results obtained on pseudohyphae formation, invasive growth capability of the pStp1-overexpressing strain is almost completely defective when compared to the control strain or the control strain transformed 


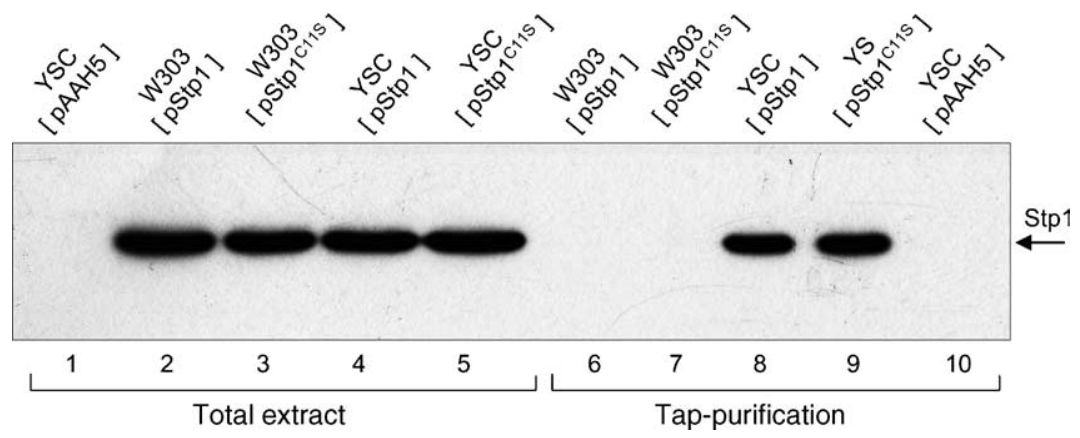

Fig. 6. Ira2 pull-down assay. Protein lysates (1 mg total proteins) from strains YSC[pAAH5]. W303[pStp1], W303 [pStp1 ${ }^{\text {C11S }}$, YSC[pStp1] and YSC $\left[p S t p 11^{\text {C11S }}\right]$ were incubated with IgG sepharose to recover the TAP-tagged Ira2 protein and the associated polipeptide(s). Crude extracts (30 $\mu \mathrm{g}$ of proteins) and purificated samples were separated by SDS-PAGE and immunoblotted for the presence of Stp1 with anti-Stp1 polyclonal antibodies.

with $\mathrm{Gpa} 2^{\text {Val132 - }}$ or Ras2 $2^{\text {Val19 }}$-expressing plasmids (Fig. 7C).

\section{Discussion}

The phosphorylation of yeast proteins on tyrosine residues was discovered in the late eighties (Grandori, Vai, Di Renzo, Alberghina, \& Popolo, 1989; Schieven, Thorner, \& Martin, 1986). Only double specificity kinases and kinases phosphorylating poly(TyrGlu) have been identified in budding yeast (Hunter \& Plowman, 1997), but no genes encoding typical tyrosine kinases are present in its genome (www.yeastgenome.org). Most yeast proteins phosphorylated on tyrosine are involved in MAP kinase pathways (Gustin et al., 1998; Hunter \& Plowman, 1997). Attempts to obtain further information on the physiological role of tyrosine phosphorylation by use of low molecular weight compounds, such as ortho-vanadate that proved to be effective in higher eukaryotes (reviewed in Walton \& Dixon, 1993) or by single or multiple deletions of phosphatase-encoding genes (Sakumoto et al., 2002), have been unsatisfactory, because of excessive toxicity (Kanik-Ennulat, Montalvo, $\&$ Neff, 1995 and references therein) or lack of detectable phenotypic effects, respectively. Furthermore, overexpression of the $S$. cerevisiae Ltp1 low molecular weight tyrosine phosphatase did not elicit any significant phenotype (data not shown; Ostanin et al., 1995). On the contrary, overexpression of Stp1, the fission yeast counterpart of Ltp1, has been shown to deeply affect the yeast proteome, as monitored by 2D electrophoresis (Modesti et al., 2001). Both Stp1 and Ltp1 (that share a 50\% sequence identity) contain the essential active-site signature sequence $\mathrm{C}-\mathrm{X}_{4}-\mathrm{C}-\mathrm{R}$ located near the $\mathrm{N}$-terminus in the phosphate binding loop and each shares a ca. $40 \%$ homology with the mammalian enzymes. Ltp1 has been shown to possess a substrate specificity similar (but not identical) to that of its mammalian counterparts and a reduced (ca. 30-fold) catalytic activity compared to that of the bovine and the $S$. pombe enzymes (Modesti et al., unpublished results). Such a relatively low activity may be due to the absence in Ltp1 of a tyrosine residue (Tyr 131), whose phosphorylation is required for maximal activation of the mammalian enzyme. Regardless of the molecular basis, the reduced specific activity of Ltp1 enzyme may explain why its overexpression fails to give detectable phenotypes. Thus, Stp1 overexpression was the only available "pharmacological" tool to elicit a defined perturbation of the balance between tyrosine phosphorylation and dephosphorylation. Accordingly, our experiments did not aim to address the substrate specificity or the physiological role of the Ltp1 enzyme, but rather aimed at identifying cellular pathways and processes affected by alteration of the yeast phosphotyrosyl-proteome. Control experiments were run on strains expressing a catalytically inactive mutant, Stp1 ${ }^{\mathrm{C} 11 \mathrm{~S}}$. Our data unambiguously indicate that such a mutant, while retaining the ability to bind to Ira2 (see later), does not produce any of the phenotypic effects observed upon expression of its catalytically competent counterpart.

The results presented in this paper show that the decreased level of cellular phosphotyrosine brought about by Stp1 expression (Modesti et al., 2001) affects nutrient-modulated cell growth/cell cycle coordination. All phenotypes displayed by Stp1-expressing strains are consistent with a down-regulation of the Ras branch of the cAMP-pathway that plays a key role in stress resistance and nutrient sensing (reviewed in Thevelein \& deWinde, 1999), although we cannot exclude that other, previously identified $S$. cerevisiae substrates for Stp1, including enzymes involved in carbon metabolism (Modesti et al., 2001) and the immunophillin Fpr3 (Magherini et al., 2004; Marchetta et al., 2004), may 

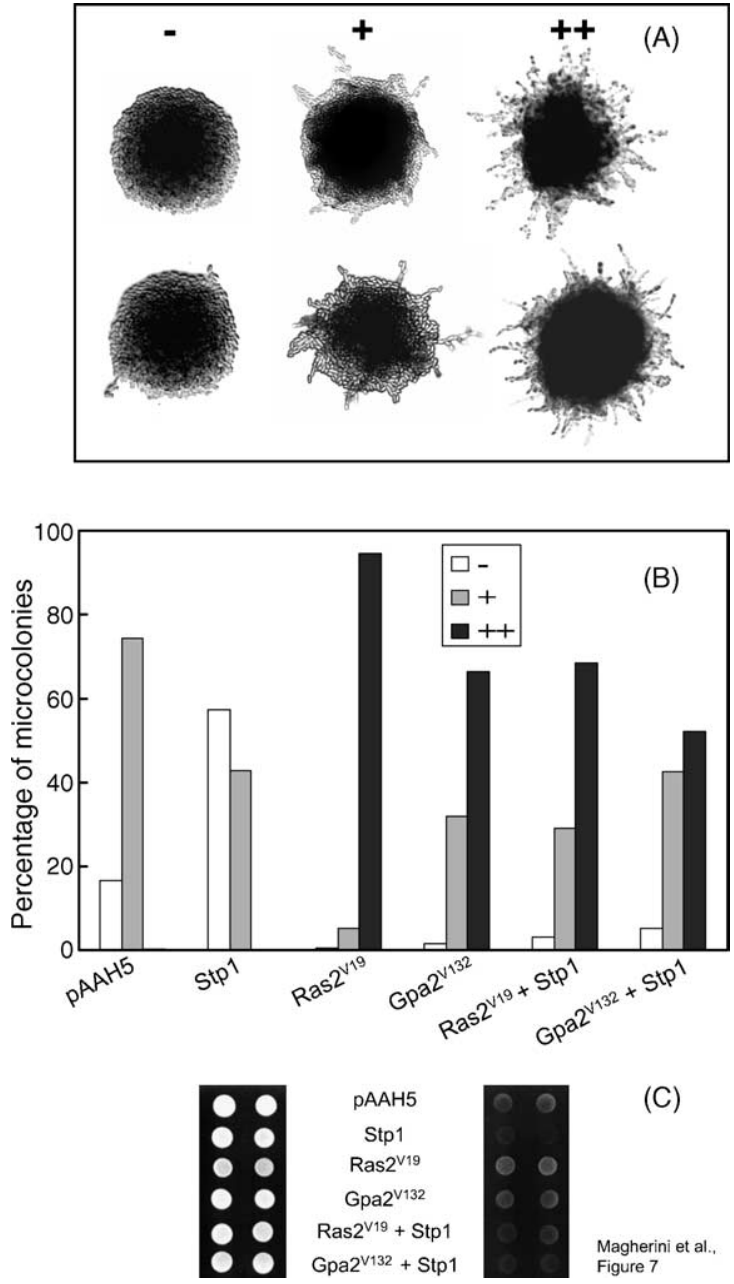

Fig. 7. Effects of Stp1 overexpression on pseudohyphal growth and invasivity. Microcolonies of diploid Nephtlys1186 strain grown on SLAD plates were grouped in three classes, according to the cell morphology phenotypes shown in (A). (B) Classes percentage of Nephtlys 1186 transformants. (C) Invasive growth of wild-type Neph11 haploid strain. The picture on the left side shows the strains which were spotted on plates, incubated for 3 days at $30^{\circ} \mathrm{C}$ and for an additional 2 days at $24^{\circ} \mathrm{C}$. Following incubation the plate was washed with water and rephotographed to yield the picture on the right side.

contribute to one or more of the phenotypes here reported. The evidence for a cross-talk between a tyrosine phosphorylation/dephosphorylation pathway(s) and the Ras/PKA pathway is many fold, since Stp1expressing cells share a number of phenotypes with mutants with attenuated Ras/PKA pathway. First, Stp1 expression affects coordination between cell-growth and cell cycle in exponentially growing cells even under conditions where growth rate is not affected, such as in glucose growing cells where a reproducible reduction in protein content is observed. When cells are grown on non-fermentable carbon sources, such as ethanol, acetate and glycerol, the observed increase in duplication time - more than $50 \%$ - can be accounted for by an increase in the unbudded, G1 phase of the cell cycle. The exquisite sensitivity of the G1/S transition to Stp1 expression was confirmed by analyzing the exit from a nitrogen starvation-induced G0 block, where delayed cycle re-entry of Stp1 expressing cells was proportional to the length of nitrogen starvation. These phenotypes are highly suggestive of a Stp1-mediated down-regulation of Start $\mathrm{B}$, i.e. the area where cell growth and division is coordinated mainly through the action of the Ras/PKA pathway.

Physiological evidence for down-regulation of the PKA pathway was given by the observed increase in heat-shock resistance, in glycogen content and in the expression of a stress responsive element (STRE) reporter gene. More compeling molecular evidence for down-regulation of Ras/cAMP signaling was obtained by studying Ras-GTP and cAMP levels following glucose addition to derepressed cells or intracellular acidification. The accumulation of cAMP takes place within minutes from addition of the sugar (Colombo et al., 1998) or DNP and it is coincident with an increase in Ras-GTP level (Colombo et al., 2004; Rudoni et al., 2001). We could show that both formation of Ras-GTP and cAMP accumulation are attenuated in Stp1 expressing strains, following either glucose or DNP addition, strongly suggesting not only that the decreased phosphotyrosine level brought about by Stp1 expression is down-regulating the Ras/PKA pathway, but that at least a major target lies in the upper portion of the pathway. Activated mutants along the Ras 2 branch of the PKA pathway (namely Ras $2^{\text {Val19 }}$ and iralira2 $\Delta$ ) (Fig. 5D and E) lost their ability to respond to Stp1 overexpression, while mutants bearing an activated GPA2 allele (Fig. 5B and C) are still able to respond to the presence of the phosphatase, although a modest reduction is seen if compared to wildtype cells. This observation suggests that $\mathrm{Gpa} 2$ protein and its upstream regulator Gpr1 may be only marginally involved, if at all, in the Stp1-dependent observed phenotypes. Consistently, the growth phenotypes of strains with deletions in either the GPR1 or GPA2 gene are quite different than those reported here (Alberghina, Rossi, Querin, Wanke, \& Vanoni, 2004). The observation that

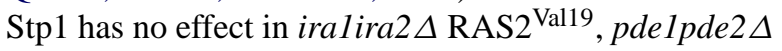
and $b c y l \Delta$ mutants suggests that the Ira proteins may be a target for Stp1 action.

Biochemical data on levels of cAMP and Ras2GTP after stimulation with glucose and DNP would indicate that tyrosine dephosphorylation of Ira proteins may result in increased Ira activity that in turn would result in the observed down-regulation of the cAMP 
pathway. Tyrosine phosphorylation of mammalian GAP has long been known (Ellis, Moran, McCormick, \& Pawson, 1990; Molloy et al., 1989; Park \& Jove, 1993) and more intriguingly p190rho-GAP has been shown to be a substrate of mammalian low molecular weight PTPase (Chiarugi et al., 2000). Furthermore it has been reported that phosphorylation of mammalian GAP by the src tyrosine kinase reduces GAP activity (Giglione, Gonfloni, \& Parmeggiani, 2001). The NetPhos expert system (Blom, Gammeltoft, \& Brunak, 1999; http://www.cbs.dtu.dk/services/NetPhos) predicts 38 and 30 tyrosine phosphorylation sites in Iral and Ira2, respectively, 8 and 9 sites showing a very high score (above 0.9). We could show that Stp1 can bind Ira2 in vivo, since Stp1 can be found as an Ira2associated protein in pull-down experiments with a Ira2-TAP-tagged strain. Ira2 is a very large protein $(\sim 350,000 \mathrm{Da})$, present in exceedingly low amounts that hampered its precise quantification in the recently published genome-wide survey of protein expression in yeast (Ghaemmaghami et al., 2003 and supplementary data; see also http://yeastgfp.ucsf.edu). Accordingly, we could not purify enough Ira2 protein to reliably detect its phosphorylation state. Nevertheless, the identification of Stp1 as an Ira2-associated protein, combined with our genetic and biochemical data, suggest that tyrosine phosphorylation/dephosphorylation of Ira proteins may contribute to the regulation of its GTPase activity. In fact, the overexpression of Stp1 ${ }^{\mathrm{C} 11 \mathrm{~S}}$, a mutant form completely devoid of Tyr-phosphatase activity, does not lead to any visible changes in cell cycle parameters or stress resistance, although this mutant can still interact with Ira2 in our pull-down assay. These findings indicate that if Stp1 is down-regulating the Ras/PKA pathway through its action on Ira2, this does not occurs because by forming a complex with Ira 2 Stp 1 prevents the binding of some negative regulator(s) to Ira2, such as Tfs1 (Chautard, Jacquet, Schoentgen, Bureaud, \& Benedetti, 2004). On the contrary, binding to Ira2 correlates with down-regulation of the Ras pathway only when Stp1 is catalytically active.

We choose to concentrate on the Ras/PKA pathway because initial experiments gave for Stp1overexpressing strain a phenotype typical of class II START mutants. Nevertheless, several other phenotypes were tested, including pseudohyphae formation/invasive growth (Fig. 7), mating factor response and osmotic shock (HOG pathway). Stp1 had no effect whatsoever on the mating or the HOG pathway (data not shown), while displaying partial effects on pseudohyphae formation and invasive growth. The role of Ras 2 in regulating the dimorphic switch in $S$. cerevisiae is two-fold, since it activates both the adenylyl cyclase/PKA and Ste/MAPK cascade (for a review, see Gancedo, 2001; Palecek et al., 2002; Pan, Harashima, \& Heitman, 2000). Both kinase pathways converge in controling the expression of $F L O 11$, a gene essential for filamentous growth (Rupp, Summers, Lo, Madhani, \& Fink, 1999). Although the effects of Stp1 on pseudohyphal/invasive growth can be rationalized by an attenuation of the Ras/PKA pathway, we cannot rule out the possibility that Stp1 may directly act on tyrosine phosphorylated proteins involved in the dimorphic switch process. Protein tyrosine phosphatases and dual specificity phosphatases are known to affect MAPKs activity in yeast. For instance, Ptp2 and Ptp3 affect localization of the Hog1 MAPK, but are also known to regulate Fus3 and Slt2 (Mattison \& Ota, 2000; Mattison, Spencer, Kresge, Lee, \& Ota, 1999; Zhan, Deschenes, \& Guan, 1997). The upper part of the Ste/MAPK cascade is shared between the pseudohyphal/invasive growth pathway and the mating pheromone response pathway and Kss1, the MAPK of the pseudohyphae/invasive growth module, has been indicated as a bona fide component of the mating pathway (Breitkreutz \& Tyers, 2002). Since Stp1 overexpression strongly reduces filamentation but does not affect $\alpha$-factor sensitivity, as detected by halo tests (data not shown), the major targets of Stp1 may lie in non-shared elements of the two pathways.

In summary, our results exclude that overexpressed Stp1, that we have used as a tool to induce an unbalance between tyrosine phosphorylation and dephosphorylation of yeast proteins, acts as an aspecific toxic compound, since overexpression of a catalytically inactive mutant fails to induce any of the effects induced by the wild-type protein. Genetic and biochemical data indicate that the catalytic activity of Stp1 down-regulates the Ras pathway by acting at, or above, the level of Ras2, possibly on the Ira proteins, thus suggesting that a physiologically relevant cross-talk between tyrosine phosphorylation and the Ras pathway exists in yeast.

\section{Acknowledgments}

The authors wish to thank friends and colleagues for gifts of strains and plasmids, Neil Campbell for proof reading of English language and the reviewers for constructive criticism. This work was partially supported by the target project on Biotechnology to G.M., the Ministero dell'Istruzione, dell'Università e della Ricerca (MIUR-PRIN 2001) to G. Camici, MIUR FAR (ex-60\%) to M.V., target project on Biotechnology and COFIN 2002 to M.V. 


\section{References}

Alberghina, L., Rossi, R. L., Querin, L., Wanke, V., \& Vanoni, M. (2004). A cell sizer network involving Cln3 and Far1 controls entrance into $\mathrm{S}$ phase in the mitotic cycle of budding yeast. J. Cell Biol., 167, 433-443.

Augenlicht, L. H., \& Baserga, R. (1974). Changes in the G0 state of WI-38 fibroblasts at different times after confluence. Exp. Cell Res., $89,255-262$.

Berben, G., Dumont, J., Gilliquet, V., Bolle, P. A., \& Hilger, F. (1991). The YDp plasmids: A uniform set of vectors bearing versatile gene disruption cassettes for Saccharomyces cerevisiae. Yeast, 7 , 475-477.

Blom, J., Gammeltoft, S., \& Brunak, S. (1999). Sequence and structurebased prediction of eukaryotic protein phosphorylation sites. $J$. Mol. Biol., 294, 1351-1362.

Breitkreutz, A., \& Tyers, M. (2002). MAPK signaling specificity: It takes two to tango. Trends Cell Biol., 12, 254-257.

Camonis, J. H., Kalekine, M., Gondre, B., Garreau, H., Boy-Marcotte, E., \& Jacquet, M. (1986). Characterization, cloning and sequence analysis of the $C D C 25$ gene which controls the cyclic AMP level of Saccharomyces cerevisiae. EMBO J., 5, 375-380.

Caselli, A., Taddei, M. L., Manao, G., Camici, G., \& Ramponi, G. (2001). Tyrosine-phosphorylated caveolin is a physiological substrate of the low M(r) protein-tyrosine phosphatase. J. Biol. Chem., $276,18849-18854$.

Chautard, H., Jacquet, M., Schoentgen, F., Bureaud, N., \& Benedetti, H. (2004). Tfs $1 p$, a member of the PEBP family, inhibits the Ira2p but not the Ira1p Ras GTPase-activating protein in Saccharomyces cerevisiae. Eukaryot. Cell., 3, 459-470.

Chiarugi, P., Cirri, P., Taddei, L., Giannoni, E., Camici, G., Manao, G., et al. (2000). The low M(r) protein-tyrosine phosphatase is involved in Rho-mediated cytoskeleton rearrangement after integrin and platelet-derived growth factor stimulation. J. Biol. Chem., 275, 4640-4646.

Cirri, P., Chiarugi, P., Camici, G., Manao, G., Raugei, G., Cappugi, G., et al. (1993). The role of Cys12, Cys17 and Arg18 in the catalytic mechanism of low-M(r) cytosolic phosphotyrosine protein phosphatase. Eur. J. Biochem., 214, 647-657.

Colombo, S., Ma, P., Cauwenberg, L., Winderickx, J., Crauwels, M., Teunissen, A., et al. (1998). Involvement of distinct G-proteins, Gpa2 and Ras, in glucose- and intracellular acidification-induced cAMP signalling in the yeast Saccharomyces cerevisiae. EMBO J., 17, 3326-3341.

Colombo, S., Ronchetti, D., Thevelein, J. M., Windedckx, J., \& Martegani, E. (2004). Activation state of the Ras 2 protein and glucoseinduced signaling in Saccharomyces cerevisiae. J. Biol. Chem., 279, 46715-46722.

Cullen, P. J., \& Sprague, GF., Jr. (2000). Glucose depletion causes haploid invasive growth in yeast. Proc. Natl. Acad. Sci. U.S.A., 97, 13461-13463.

Damak, F., Boy-Marcotte, E., Le-Roscouet, D., Guilbaud, R., \& Jacquet, M. (1991). SDC25, a CDC25-like gene which contains a RAS-activating domain and is a dispensable gene of Saccharomyces cerevisiae. Mol. Cell. Biol., 11, 202-212.

Ellis, C., Moran, M., McCormick, F., \& Pawson, T. (1990). Phosphorylation of GAP and GAP-associated proteins by transforming and mitogenic tyrosine kinases. Nature, 343, 377-381.

Francois, J., Villanueva, M. E., \& Hers, H. G. (1998). The control of glycogen metabolism in yeast. 1. Interconversion in vivo of glycogen synthase and glycogen phosphorylase induced by glucose, a nitrogen source or uncouplers. Eur. J. Biochem., 174, 551-559.
Gancedo, J. M. (2001). Control of pseudohyphae formation in Saccharomyces cerevisiae. FEMS Microbiol. Rev., 25, 107-123.

Gavin, A. C., Bosche, M., Krause, R., Grandi, P., Marzioch, M., Bauer, A., et al. (2002). Functional organization of the yeast proteome by systematic analysis of protein complexes. Nature, 415, 141-147.

Ghaemmaghami, S., Huh, W. K., Bower, K., Howson, R. W., Belle, A., Dephoure, N., et al. (2003). Global analysis of protein expression in yeast. Nature, 425, 737-741.

Giglione, C., Gonfloni, S., \& Parmeggiani, A. (2001). Differential actions of p60c-Src and Lck kinases on the Ras regulators p120GAP and GDP/GTP exchange factor CDC25 $5^{\mathrm{Mm}}$. Eur. J. Biochem., 268, 3275-3283.

Gimeno, C. J., Ljungdahl, P. O., Styles, C. A., \& Fink, G. R. (1992). Unipolar cell divisions in the yeast $S$. cerevisiae lead to filamentous growth: Regulation by starvation and RAS. Cell, 68, 10771090.

Grandori, R., Vai, M., Di Renzo, M. F., Alberghina, L., \& Popolo, L. (1989). Identification of a protein cross-reacting with antiphosphotyrosine antibodies in yeast insoluble cytoplasmic matrices. Biochem. Biophys. Res. Commun., 160, 887-896.

Gustin, M. C., Albertyn, J., Alexander, M., \& Davenport, K. (1998). MAP kinase pathways in the yeast Saccharomyces cerevisiae. Microbiol. Mol. Biol. Rev., 62, 1264-1300, Review.

Hunter, T., \& Plowman, G. D. (1997). The protein kinases of budding yeast: Six score and more. Trends Biochem. Sci., 22, 18-22, Review.

Iida, H., \& Yahara, I. (1984). Specific early G1 blocks accompanied with stringent response in Saccharomyces cerevisiae lead to growth arrest in resting state similar to the G0 of higher eukaryotes. J. Cell Biol., 98, 1185-1192.

Jiang, Y., Davis, C., \& Broach, J. R. (1998). Efficient transition to growth on fermentable carbon sources in Saccharomyces cerevisiae requires signaling through the Ras pathway. EMBO J., 17, 6942-6951.

Kanik-Ennulat, C., Montalvo, E., \& Neff, N. (1995). Sodium orthovanadate-resistant mutants of Saccharomyces cerevisiae show defects in Golgi-mediated protein glycosylation, sporulation and detergent resistance. Genetics, 140, 933-943.

Keyse, S. M. (2000). Protein phosphatases and the regulation of mitogen activated protein kinase signalling. Curr. Opin. Cell Biol., 12, 186-192.

Kraakman, L., Lemaire, K., Ma, P., Teunissen, A. W. R. H., Donaton, M. C. V., Van Dijck, P., et al. (1999). A Saccharomyces cerevisiae G-protein coupled receptor, Gpr1, is specifically required for glucose activation of the cAMP pathway during the transition to growth on glucose. Mol. Microbiol., 32, 1002-1012.

Liu, H., Styles, C. A., \& Fink, G. R. (1993). Elements of the yeast pheromone response pathway required for filamentous growth of diploids. Science, 262, 1741-1744.

Lorenz, M. C., \& Heitman, J. (1997). Yeast pseudohyphal growth is regulated by $\mathrm{Gpa} 2$, a $\mathrm{G}$ protein alpha homolog. EMBO J., 16, 7008-7018.

Ma, P., Wera, S., Van Dijck, P., \& Thevelein, J. M. (1999). The PDE1encoded low-affinity phosphodiesterase in yeast Saccharomyces cerevisiae has a specific function in controlling agonist-induced cAMP signalling. Mol. Biol. Cell, 10, 91-104.

Magherini, F., Gamberi, T., Paoli, P., Marchetta, M., Biagini, M., Raugei, G., et al. (2004). Biochem. Biophys. Res. Commun., 20, 424-431.

Marchetta, M., Gamberi, T., Sarno, S., Magherini, F., Raugei, G., Camici, G., et al. (2004). Expression of the Stp1 LMW-PTP and inhibition of protein CK2 display a cooperative effect on 
immunophilin Fpr3 tyrosine phosphorylation and Saccharomyces cerevisiae growth. Cell. Mol. Life Sci., 61, 1176-1184.

Mattison, C. P., \& Ota, I. M. (2000). Two protein tyrosine phosphatases, Ptp2 and Ptp3, modulate the subcellular localization of the Hog1 MAP kinase in yeast. Genes Dev., 15, 1229-1235.

Mattison, C. P., Spencer, S. S., Kresge, K. A., Lee, J., \& Ota, I. M. (1999). Differential regulation of the cell wall integrity mitogenactivated protein kinase pathway in budding yeast by the protein tyrosine phosphatases Ptp2 and Ptp3. Mol. Cell. Biol., 19, 7651-7660.

Modesti, A., Bini, L., Carraresi, L., Magherini, F., Liberatori, S., Pallini, V., et al. (2001). Expression of the small tyrosine phosphatase (Stp1) in Saccharomyces cerevisiae: A study on protein tyrosine phosphorylation. Electrophoresis, 22, 576-585.

Modesti, A., Cirri, P., Raugei, G., Carraresi, L., Magherini, F., Manao, G., et al. (1995). Expression, purification and kinetic behaviour of fission yeast low M(r) protein-tyrosine phosphatase. FEBS Lett., 375, 235-238.

Molloy, C. J., Bottaro, D. P., Fleming, T. P., Marshall, M. S., Gibbs, J. B., \& Aaronson, S. A. (1989). PDGF induction of tyrosine phosphorylation of GTPase activating protein. Nature, 342, 711-714.

Mondesert, O., Moreno, S., \& Russel, P. (1994). Low molecular weight protein-tyrosine phosphatases are highly conserved between fission yeast and man. J. Biol. Chem., 269, 27996-27999.

Moskivna, E., Schuller, C., Mauer, C. T. C., Mager, W. H., \& Ruis, H. (1998). A search in the genome of Saccharomyces cerevisiae for genes regulated via stress response elements. Yeast, 14, 1041-1050.

Müller, G., Rouveyre, N., Crecelius, A., \& Bandlow, W. (1998). Insulin signaling in the yeast Saccharomyces cerevisiae. 1. Stimulation of glucose metabolism and Snf1 kinase by human insulin. Biochemistry, 37, 8683-8695.

Nikawa, J., Sass, P., \& Wigler, M. (1987). Cloning and characterization of the low-affinity cyclic AMP phosphodiesterase gene of Saccharomyces cerevisiae. Mol. Cell. Biol., 7, 3629-3636.

Ostanin, K., Pokalsky, C., Wang, S., \& Van Etten, R. L. (1995). Characterization of a Saccharomyces cerevisiae gene encoding the low molecular weight protein tyrosine phosphahatase. J. Biol. Chem., 270, 18491-18499.

Palecek, S. P., Parikh, A. S., \& Kron, S. J. (2002). Sensing, signalling and integrating physical processes during Saccharomyces cerevisiae invasive and filamentous growth. Microbiology, 148, 893-907.

Pan, X., Harashima, T., \& Heitman, J. (2000). Transduction cascades regulating pseudohyphal differentiation of Saccharomyces cerevisiae. Curr. Opin. Microbiol., 3, 567-572.

Park, S., \& Jove, R. (1993). Tyrosine phosphorylation of Ras GTPaseactivating protein stabilizes its association with p62 at membranes of v-Src transformed cells. J. Biol. Chem., 268, 25728-25734.

Rigaut, G., Shevchenko, A., Rutz, B., Wilm, M., Mann, M., \& Seraphin, B. (1999). A generic protein purification method for protein complex characterization and proteome exploration. Nat. Biotechnol., 17, 1030-1032.

Roberts, R. L., \& Fink, G. R. (1994). Elements of a single MAP kinase cascade in Saccharomyces cerevisiae mediate two developmental programs in the same cell type: Mating and invasive growth. Genes Dev., 8, 2974-2985.

Robinson, L. C., Gibbs, J. B., Marshall, M. S., Sigal, I. S., \& Tatchell, K. (1987). CDC25: A component of the RAS-adenylate cyclase pathway in Saccharomyces cerevisiae. Science, 235, 1218-1221.

Rolland, F., Winderickx, J., \& Thevelein, J. M. (2002). Glucosesensing and -signalling mechanisms in yeast. FEMS Yeast Res., 2, 183-201.
Rudoni, S., Colombo, S., Coccetti, P., \& Martegani, E. (2001). Role of guanine nucleotides in the regulation of the Ras/cAMP pathway in Saccharomyces cerevisiae. Biochem. Biophys. Acta, 1538, 181-189.

Ruis, H., \& Schuller, C. (1995). Stress signalling in yeast. Bioessays, 17, 959-965.

Rupp, S., Summers, E., Lo, H. J., Madhani, H., \& Fink, G. (1999). MAP kinase and cAMP filamentation signaling pathways converge on the unusually large promoter of the yeast FLO11 gene. EMBO J., 18, 1257-1269.

Russell, P., Moreno, S., \& Reed, S. I. (1989). Conservation of mitotic controls in fission and budding yeasts. Cell, 57, 295-303.

Sakumoto, N., Matsuoka, I., Mukai, Y., Ogawa, N., Kaneko, Y., \& Harashima, S. (2002). A series of double disruptants for protein phosphatase genes in Saccharomyces cerevisiae and their phenotypic analysis. Yeast, 19, 587-599.

Sass, P., Field, J., Nikawa, J., Toda, T., \& Wigler, M. (1986). Cloning and characterization of the high-affinity cAMP phosphodiesterase of Saccharomyces cerevisiae. Proc. Natl. Acad. Sci., 83, 9303-9307.

Schieven, G., Thorner, J., \& Martin, G. S. (1986). Proteintyrosine kinase activity in Saccharomyces cerevisiae. Science, 231, 390-393.

Smith, A., Ward, M. P., \& Garrett, S. (1998). Yeast PKA represses Msn2p/Msn4p-dependent gene expression to regulate growth, stress response and glycogen accumulation. EMBO J., 11, 3556-3564.

Taddei, M. L., Chiarugi, P., Cirri, P., Talini, D., Camici, G., Manao, G., et al. (2000). LMW-PTP exerts a differential regulation on PDGFand insulin-mediated signalling. Biochem. Biophys. Res. Commun., $13,564-569$.

Tanaka, K., Nakafuku, M., Satoh, T., Marshall, M. S., Gibbs, J. B., Matsumoto, K., et al. (1990). S. cerevisiae genes IRA1 and IRA2 encode proteins that may be functionally equivalent to mammalian ras GTPase activating protein. Cell, 60, 803-807.

Thevelein, J. M., \& deWinde, J. H. (1999). Novel sensing mechanisms and targets for the cAMP-protein kinase A pathway in the yeast Saccharomyces cerevisiae. Mol. Microbiol., 33, 904-918.

Thomas, B. J., \& Rothstein, R. (1989). Elevated recombination rates in transcriptionally active DNA. Cell, 56, 619-630.

Toda, T., Uno, I., Ishikawa, T., Powers, S., Kataoka, T., Broek, D., et al. (1985). In yeast, Ras proteins are controlling elements of adenylate cyclase. Cell, 40, 27-36.

Van der Geer, P., Hunter, T., \& Lindberg, R. (1994). Receptor proteintyrosine kinases and their signal transduction pathways. Annu. Rev. Cell. Biol., 10, 251-337.

Van der Plaat, J. B. (1974). Cyclic 3',5'-adenosine monophosphate stimulates trehalose degradation in baker's yeast. Biochem. Biophys. Res. Commun., 56, 580-587.

Vanoni, M., \& Johnson, S. P. (1991). Phosphorylation of ribosomal protein S10 is dispensable for initiation of DNA replication and bud emergence in Saccharomyces cerevisiae. Eur. J. Cell Biol., 55, 179-182.

Vanoni, M., Vai, M., Popolo, L., \& Alberghina, L. (1983). Structural heterogeneity in populations of the budding yeast Saccharomyces cerevisiae. J. Bacteriol., 156, 1282-1291.

Varela, J. C., Praekelt, U. M., Meacock, P. A., Planta, R. J., \& Mager, W. H. (1995). The Saccharomyces cerevisiae HSP 12 gene is activated by the high-osmolarity glycerol pathway and negatively regulated by protein kinase A. Mol. Cell. Biol., 15, 6232-6245.

Walton, K. M., \& Dixon, J. E. (1993). Protein tyrosine phosphatases. Апnи. Rev. Biochem., 62, 101-120. 
Wanke, V., Accorsi, A., Porro, D., Esposito, F., Russo, T., \& Vanoni, M. (1999). In budding yeast, reactive oxygen species induce both RAS-dependent and independent cell cycle-specific effects. Mol. Microbiol., 32, 753-764.

Xue, Y., Batlle, M., \& Hirsch, J. P. (1998). GPR1 encodes a putative G protein-coupled receptor that associates with the $G p a 2 p \mathrm{G}_{\alpha}$ subunit and functions in a Ras-independent pathway. EMBO J., 17, 1996-2007.
Zhan, X. L., Deschenes, R. J., \& Guan, K. L. (1997). Differential regulation of FUS3 MAP kinase by tyrosinespecific phosphatases PTP2/PTP3 and dual-specificity phosphatase MSG5 in Saccharomyces cerevisiae. Genes Dev., 11, 16901702.

Zhu, H., Klemic, J. F., Chang, S., Bertone, P., Casamayor, A., Klemic, K. G., et al. (2000). Analysis of yeast protein kinase using protein chips. Nat. Genet., 26, 283-289. 